\title{
Rede de herança para construções complexas subjetivas
}

DOI: http://dx.doi.org/10.21165/el.v49i2.2621

\section{Sebastião Carlos Leite Gonçalves ${ }^{1}$}

\section{Resumo}

Este artigo trata de construções complexas, sob a perspectiva dos Modelos Baseados no Uso (BARLOW; KEMMER, 2000), que assumem a construção como unidade de análise, um pareamento simbólico de forma e sentido. Recorrendo-se a dados de fala do português brasileiro e, a partir do esquema genérico [[Argumento][Predicado]], organiza-se uma rede de herança para construções complexas subjetivas, considerando-se se ocorre ou não topicalização de Sujeito ou Objeto encaixado para o domínio de sua matriz. Assentada em princípios cognitivos relevantes (GOLDBERG, 1995), a rede de herança comprova a adequação da abordagem construcional para o tratamento também de construções complexas.

Palavras-chave: Modelos Baseados no Uso; rede de herança; construções subjetivas; topicalização.

1 Universidade Estadual Paulista "Júlio de Mesquita Filho" (UNESP), São José do Rio Preto, São Paulo, Brasil; sebastiao.goncalves@unesp.br; https://orcid.org/0000-0002-1798-729X 


\title{
Inheritance network for subjective complex constructions
}

\begin{abstract}
This paper deals with complex constructions, under perspective of Usage-Based Models (BARLOW; KEMMER, 2000), which assumes the construction as its unit of analysis, a symbolic pairing of form and meaning. Using Brazilian Portuguese speech data and starting from the generic scheme [[Argument] [Predicate]], an inheritance network is organized for subjective complex constructions, arranged in sublevels, considering whether or not topicalization of embedded Subject or Object for the domain of its matrix occurs. Based on cognitive principles (GOLDBERG, 1995), the inheritance network proves the adequacy of the constructional framework for treating also complex constructions.
\end{abstract}

Keywords: Usage-based Models; inheritance network; subjective constructions; topicalization.

\section{Introdução}

Este artigo trata da proposição de uma rede de herança de construções argumentais complexas do português brasileiro, situando, nela, o caso particular de construções complexas subjetivas (CCS), tradicionalmente reconhecidas como orações subordinadas subjetivas. Ao propor essa rede de herança, argumenta-se em favor da adequação da abordagem construcional para o tratamento também de construções complexas instanciadas por subordinação, aqui entendida, em sentido estrito, como o ambiente sintático em que se reconhece entre as partes do complexo oracional uma relação do tipo [[Pred(icado] [Arg(umento)]]. Essa relação restringe a noção mais tradicional de subordinação, para nela incluir casos de construções sintáticas complexas que, nucleadas por um elemento com papel predicador, expressam relação de predicação entre duas construções, e, ao mesmo tempo, dela remover casos de construções sintáticas complexas nas quais uma das partes constitutivas ocorre como adjunto, expressando relações de circunstâncias variadas, como de causa, condição, concessão, tempo etc. ${ }^{2,3}$.

No desenvolvimento dessa proposta, pretende-se, então, confrontar propriedades de forma e sentido das construções em análise, visando estabelecer entre elas relações de herança, a serem atestadas por princípios psicológicos relevantes para a organização

\footnotetext{
2 Para uma visão geral de como construções complexas que expressam relações de circunstância podem também receber um tratamento dentro da abordagem construcional, ver trabalho de Gonçalves e Oliveira (2020), a sair, em breve, como artigo completo.

3 Ao longo do artigo, as seguintes notações são recorrentes: $\mathrm{PB}=$ português brasileiro; $\mathrm{MBU}$ = Modelos Baseados no Uso; GC = Gramática de Construções; CCS = Construção complexa subjetiva; Pred = Predicado; $\operatorname{Arg}=$ Argumento; Suj = Sujeito; Obj = Objeto; Top = Tópico .
} 
linguística de redes construcionais (GOLDBERG, 1995, 2003). Para isso, assumemse as bases teóricas dos chamados Modelos Baseados no Uso (LANGACKER, 1987; BARLOW; KEMMER, 2000; BYBEE, 2016), associadas a postulados da Gramática de Construções (GOLDBERG, 1995, 2003; CROFT, 2001; TRAUGOTT; TROUSDALE, 2013). As análises assentam-se em dados de CCS de amostras de fala do PB contemporâneo, já apresentados e discutidos anteriormente (GONÇALVES, 2001, 2009, 2011, 2012, 2015, 2016 e 2017), mas sob outras perspectivas teóricas.

Assumindo, então, a construção como unidade de análise, justifica-se o objetivo último de propor uma rede de construções argumentais complexas onde seja possível situar o caso das CCS, em razão de, na abordagem construcional, maior ênfase ser dispensada ao tratamento de construções argumentais simples (transitivas, ditransitivas, por exemplo) ou mesmo à formação de conectivos oracionais, com pouca atenção ainda para construções complexas resultantes de processos de combinação de oração.

Apresentada a proposta geral que aqui se desenvolve, o artigo segue estruturado em três outras seções principais: na primeira seção, delimita-se o fenômeno gramatical em análise, as CCS e seus subtipos; na segunda seção, apresentam-se as bases teóricas dos $M B U$, sob as quais o fenômeno é analisado, para, na terceira seção, se alcançar o objetivo principal, a formulação de uma rede de herança, na qual se implementam os padrões de CCS. Fecham o artigo as conclusões, seguindo-se as referências.

\section{Delimitando o objeto de investigação}

Revisitam-se, neste artigo, resultados de investigações anteriores acerca de CCS, tratandose, agora, de aspectos ainda não contemplados (GONÇALVES, 2001, 2009, 2011, 2012, 2015, 2016 e 2017), sobretudo os voltados para processos cognitivos explicativos da topicalização de constituintes argumentais da construção subordinada. Tal empreitada requer que se considerem três diferentes tipos de CCS, como os exemplificados nas ocorrências de (1) a (3) ${ }^{4}$, nas quais se representam: (i) a construção alvo da análise e suas subpartes entre colchetes ([...]); (ii) as construções matrizes relevantes, em negrito; (iii) Sujeito/Objeto do predicado encaixado, em sublinhado; (iv) paráfrases de construção com topicalização, em alguns casos, antecedidas do sinal de "igual" (=), para mostrar sua relação com construção sem topicalização.

4 Abaixo de cada ocorrência, entre colchetes, aparecem identificados como: BDI, o Banco de dados Iboruna (http://www.unesp.iboruna.ibilce.unesp.br) (GONÇALVES, 2007), de onde provém os dados; AC, a Amostra Censo do BDI; L., a linha de localização da ocorrência, seguida do número do inquérito. 
a. Acho que na época do Mané né? ... [[parece] [que a cidade estagnô(u) um po(u)co]] né?

[BDI; AC-118; L. 658]

b. [[é difícil] [alguém acreditá(r) nessas coisas]] né?

[BDI; AC-15; L. 261]

c. saben(d)o as peças que você tá mexen(d)o ... éh.: [[fica fácil] [pra consertá(r) as coisa]]

[BDI; AC-29; L. 171]

(2) Tipo-2: CCS com Sujeito topicalizado

a. ele CHOra de um jeito que [[aquilo parece] [que toca lá no fundo da gente]]

$=$ [[parece] [que aquilo toca lá no fundo da gente]]

[BDI; AC-86; L.839]

b. [[eu sô(u) assim muito difícil] [pa aprendê( $r)$ a fazê( $(r)$ as coisas]]

[= [[é muito difícil] [para eu aprender a fazer as coisas]]

[BDI; AC-36; L.268]

(3) Tipo-3: CCS com Objeto topicalizado

a. quando o aluno tem dom ... [[ele é muito mais fácil] [do professor ensiná(r)]]

= [[é muito mais fácil] [de o professor ensinar ele]

[AC-109; L. 620]

b. [[massa podre ela fica um po(u)QUI:::nho difícin][de... de abri(r)]]

= [[fica um pouquinho difícil] [de abrir massa podre] $]$

[AC-134; L. 249]

A configuração estrutural prototípica de CCS, coincidente com a do Tipo 1, permite que Sujeito e Objeto da construção encaixada sejam topicalizados eocorram fora de sua posição argumental, como se observa na configuração dos Tipos 2 e 3, mais especificamente na periferia à esquerda da construção matriz. Interessa, portanto, focalizar propriedades de CCS prototípicas como motivadoras de construções com topicalização de Sujeito e Objeto, sob a hipótese geral de que estes dois últimos tipos se instanciam, na língua, por processo cognitivo de analogização a outros tipos de construções argumentais altamente produtivos, herdando deles traços de forma e de função. Defende-se aqui a existência de uma rede de herança entre construções argumentais do PB, motivada nas seguintes bases: (i) um esquema construcional abstrato [[Arg(umento)] [Pred]], predominante no sistema linguístico, independentemente da ordenação e da complexidade interna de suas subpartes, estrutura diversos subesquemas construcionais, tanto simples como 
complexos; (ii) CCS, como subesquemas, instanciam três tipos de padrões construcionais organizados em subníveis: um subnível mais esquemático, para CCS prototípicas; um subnível intermediário, para CCS com matrizes impessoais epistêmica ou avaliativa, sem topicalização; um subnível mais baixo na rede, para dois padrões de CCS com topicalização: um para Sujeito em matriz epistêmica ou avaliativa, e outro para Objeto em matriz somente avaliativa.

\section{Bases teóricas}

A análise do objeto sob investigação assenta-se nas bases teóricas dos $M B U$, que conjugam postulados do Funcionalismo e do Cognitivismo norte-americanos. Também importante para as análises propostas é a noção givoniana de Topicalização. Tais construtos seguem expostos nas duas próximas subseções.

\section{Modelos Baseados no Uso (MBU) e Gramática de construções}

Cunhado inicialmente por Langacker (1987), o rótulo MBU identifica, hoje, uma corrente teórica que advoga que a língua é um sistema adaptativo complexo que exibe, ao mesmo tempo, estrutura, variação e gradiência, e não deve, portanto, ser considerada produto acabado, mas sempre emergente do uso ao qual nossas habilidades cognitivas sempre se adaptam (BYBEE, 2016).

Segundo Barlow e Kemmer (2000), os MBU se movimentam em torno de oito princípios básicos, que seguem sumarizados no quadro 1, a seguir.

Quadro 1. Princípios teórico-metodológicos dos MBU

\begin{tabular}{|l|l|}
\hline Princípio & Explicitação \\
\hline $\begin{array}{l}\text { 1. Importância da } \\
\text { frequência de uso }\end{array}$ & $\begin{array}{l}\text { A frequência de uso de um padrão particular é tanto resultado quanto } \\
\text { força de moldagem do sistema, porque a rotinização cognitiva de uma } \\
\text { unidade linguística afeta o modo de seu processamento. }\end{array}$ \\
\hline $\begin{array}{l}\text { 2. Compreensão } \\
\text { e produção } \\
\text { integradas ao } \\
\text { sistema linguístico }\end{array}$ & $\begin{array}{l}\text { Eventos de uso dirigem a formação e o funcionamento do sistema } \\
\text { linguístico, não se admitindo separação entre estrutura e atos do } \\
\text { processamento mental que ocorre no uso da língua; como performance } \\
\text { é porte de competência, "erros de performance" conformam-se ou não a }\end{array}$ \\
\hline $\begin{array}{l}\text { 3. Foco na diferentes graus. } \\
\text { experiência durante } \\
\text { o processo de } \\
\text { aquisição da } \\
\text { linguagem }\end{array}$ & $\begin{array}{l}\text { Produção e compreensão linguísticas são significantes na aquisição } \\
\text { da linguagem, sendo desnecessário postular estruturas linguísticas } \\
\text { geneticamente especificadas; o estágio inicial da aquisição é marcado } \\
\text { por poucas estruturas; é do uso da língua que a criança vai abstraindo } \\
\text { padrões construcionais mais gerais. }\end{array}$ \\
\hline
\end{tabular}




\begin{tabular}{|l|l|}
\hline $\begin{array}{l}\text { 4. Emergência das } \\
\text { representações } \\
\text { linguísticas }\end{array}$ & $\begin{array}{l}\text { Como rotinas cognitivas de padrões mentalmente ativados, unidades } \\
\text { linguísticas não são "estocadas" em qualquer localização neural } \\
\text { particular, porque são sempre emergentes do uso. }\end{array}$ \\
\hline $\begin{array}{l}\text { 5. Importância } \\
\text { de dados de uso } \\
\text { na construção de } \\
\text { teorias }\end{array}$ & $\begin{array}{l}\text { O estudo da língua deve se pautar pelo que as pessoas produzem e } \\
\text { entendem; teorias devem ser fundamentadas na observação de dados } \\
\text { de uso real, e não em intuições; dados de corpora trazem insights para } \\
\text { questões linguísticas relevantes. }\end{array}$ \\
\hline $\begin{array}{l}\text { 6. Íntima relação } \\
\text { entre uso, variação } \\
\text { sincrônica e } \\
\text { mudança diacrônica }\end{array}$ & $\begin{array}{l}\text { Quanto mais interagem, mais os usuários tendem à padronização } \\
\text { da variação; o uso é lócus de mudança, e o falante, fonte de } \\
\text { micromudanças diacrônicas em seu próprio sistema e no de outros; em } \\
\text { cada estágio da mudança, as mesmas motivações operam, afetando } \\
\text { atos de percepção e de produção. }\end{array}$ \\
\hline $\begin{array}{l}\text { 7. Relação entre } \\
\text { sistema linguístico } \\
\text { e processos } \\
\text { cognitivos gerais }\end{array}$ & $\begin{array}{l}\text { Processos de abstração linguística não são diferentes dos que ocorrem } \\
\text { em outros domínios cognitivos, porque estrutura linguística é parte de } \\
\text { estruturas conceituais; modelos cognitivos e culturais são quadros para } \\
\text { o entendimento do significado das expressões linguísticas. }\end{array}$ \\
\hline $\begin{array}{l}\text { 8. Papel do contexto } \\
\text { no funcionamento } \\
\text { do sistema } \\
\text { linguístico }\end{array}$ & $\begin{array}{l}\text { O significado não está na estrutura em si; contextos de uso (linguísticos } \\
\text { e não linguísticos) influenciam todos os aspectos da língua e revelam } \\
\text { complexa interação com representações cognitivas abstraídas da } \\
\text { experiência. }\end{array}$ \\
\hline
\end{tabular}

Fonte: Adaptado de Barlow e Kemmer (2000)

Esses princípios levam ao entendimento de que a dinâmica das línguas confere a elas relativa estabilidade, sem necessidade de aplicação de regras fixas a qualquer situação. Subjaz a eles a crença de que a relação entre a representação abstrata da gramática e os eventos de uso é muito mais direta do que o que se assume em outros modelos de gramática. Concebe-se, assim, que o abstrato e o particular estão fortemente relacionados, pois é da repetição de exemplares específicos da língua que, gradualmente, se abstraem representações mais gerais. A relação entre padrões gerais, ou simplesmente esquemas, e suas realizações específicas traz consequências para a gramática das línguas, cujas unidades não são fixas, mas dinâmicas, porque estão sempre sujeitas à extensão criativa e são constantemente reformatadas com o uso.

Bybee (2016) considera que, na busca de explicações das propriedades observadas nas estruturas linguísticas, processos específicos às línguas podem ser mais bem compreendidos à luz de processos cognitivos mais gerais, tais como: categorização (representações com base em protótipos), chunking (sequências de processamento simples e automatizado), memória enriquecida (estocagem na mente de detalhes da experiência), analogia (criações com base em experiências prévias) e associação transmodal (elo de ligação entre experiências coocorrentes). Na construção de teorias 
linguísticas mais coerentes e econômicas, investigar a atuação desses processos sobre as representações linguísticas implica reconhecer que é possível "derivar a língua da não língua" (BYBEE, 2016, p. 196). Assim, os MBU rejeitam a autonomia da sintaxe e conjugam a semântica e a pragmática na análise da estrutura linguística.

Levando em conta esses princípios, os MBU assumem a construção como unidade de análise mais adequada para a representação morfológica e sintática, sem distinção entre léxico e gramática, pois o que se defende é que os usuários da língua armazenam padrões construcionais, e não informações lexicais individuais. A construção (de morfemas a, até mesmo, padrões textuais), definida como unidade simbólica e convencional da gramática, representa uma rotina consolidada, que, geralmente usada "de modo convencional" na comunidade de fala, envolve pareamento ("simbólico") de forma e significado, tal como a representa Croft (2001) na figura 1.

Figura 1. A estrutura simbólica de uma construção

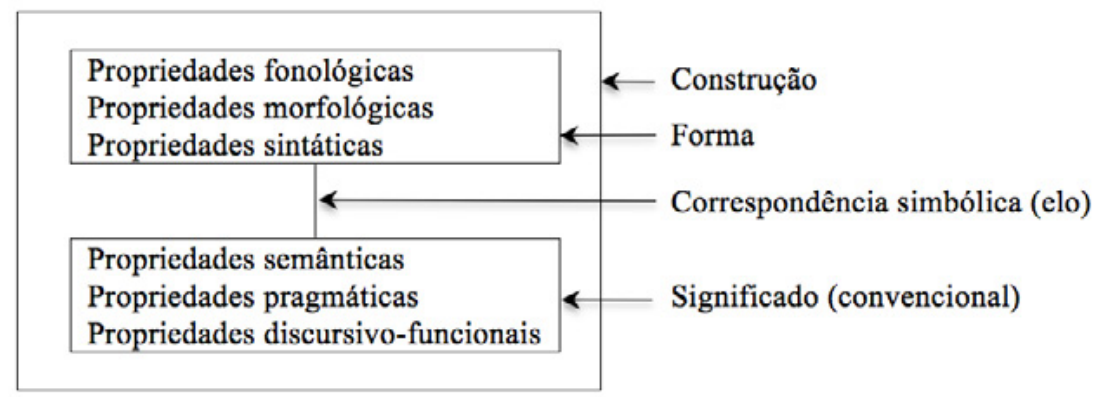

Fonte: Croft (2001, p. 18, tradução nossa)

Sob essa representação, a construção, como entidade teórica, é um esquema abstrato capaz de reunir semelhanças entre elementos de mesma natureza, tornando-se, assim, essencial para descrever padrões não usuais, especialmente complexos, e padrões regulares, básicos, da língua, sem necessidade de derivação de um padrão de outro. Segundo Goldberg (2003), generalizações particulares podem ser captadas por redes de herança entre construções: esquemas genéricos são abstraídos de padrões construcionais mais restritos (subesquemas) que, situados em pontos mediais da rede, sancionam padrões particulares de níveis mais baixos.

Para construção de redes de herança, Goldberg (1995, p. 67-68) propõe que se verifique a aplicação dos quatro princípios básicos explicitados em (4).

(4) Princípios psicológicos relevantes para organização linguística de redes construcionais

i. Motivação maximizada: entre duas construções sintaticamente relacionadas deve haver motivações semânticas e pragmáticas. 
ii. Não-sinonímia: entre construções sintaticamente diferentes deve haver também diferenças semânticas e/ou pragmáticas.

Corolário A: duas construções sintaticamente distintas e semanticamente sinônimas devem ser pragmaticamente distintas. Aspectos pragmáticos particulares da construção envolvem estrutura da informação (Tópico e Foco) e aspectos estilísticos, como registro.

Corolário B: duas construções sintaticamente distintas e pragmaticamente sinônimas devem ser semanticamente distintas.

iii. Poder expressivo maximizado: o inventário de construções é maximizado para atender a propósitos comunicativos.

iv. Economia maximizada: diante do Princípio (iii), o número de construções distintas é minimizado tanto quanto possível.

Partindo desses princípios, Goldberg (1995) deriva quatro tipos de ligações entre construções em rede: i) por polissemia (relação entre um sentido específico e alguma extensão desse sentido); ii) por subpartes (partes de uma construção mais ampla existem independentemente como construções particulares); iii) por instanciação (elementos fixos de uma construção específica podem instanciar outra construção); iv) por extensão metafórica (da projeção do sentido de uma construção, pode-se construir outra construção de um outro domínio semântico).

Traugott e Trousdale (2013), tratando de mudanças que levam a modificações em uma rede construcional, ou por construcionalização (formação na rede de novas construções com funções procedurais) ou por mudança construcional (alterações na forma e/ou no sentido de uma construção já formada), propõem a verificação dos seguintes parâmetros intervenientes: (i) esquematicidade: abstração da construção a partir de exemplares específicos; (ii) produtividade: habilidade de uma construção em atrair construções menos esquemáticas, via analogização; (iii) composicionalidade: derivação ou não do significado da construção de suas subpartes. Os dois tipos de mudança previstos podem afetar os diferentes níveis construcionais de uma rede: o das macroconstruções (ou esquemas abstratos), reservado a esquemas altamente abstratos, é pouco suscetível à atração semântica de outras construções; o das mesoconstruções (ou subesquemas), por agrupar microconstruções com traços semânticos e sintáticos comuns, já pode atrair novas construções, por analogização; o das microconstruções, agrupando tipos de construções individuais alinhadas a mesoconstruções, mantém suas idiossincrasias de forma e sentido, por conta de itens específicos recrutados na sua formação; e, o último nível, o dos construtos, é o lugar de representação de instâncias de uso responsáveis por qualquer tipo de inovação na rede mais ampla. 


\section{Topicalização de constituintes argumentais}

Langacker (1995) argumenta que, mais do que funções semânticas e sintáticas de constituintes argumentais de uma construção, em termos cognitivo-funcionais, é a saliência cognitiva de uma cena ou de um de seus participantes que explicaria o fato de Sujeito e Objeto poderem ou não receber proeminência focal em uma construção argumental, e não a simples natureza "gramatical lógica" da construção. A saliência cognitiva de que trata o autor pode ser apreciada na base de fatores semânticopragmáticos, como definitude, topicalidade, animacidade e status informacional de um dado referente discursivo, os quais determinam sua acessibilidade num discurso corrente, como propõe Givón $(2001,2012)$.

Segundo Givón (2012), dependendo do grau de dificuldade que o falante assume que o ouvinte possa ter na identificação de um referente de discurso, a construção de tópico ocorre como estrutura marcada. É nesse sentido que, segundo o autor, "Sujeito-tópico serve como ponto de continuidade, o leitmotif, o fio sobre o qual os humanos fazem afirmações em cadeias multiproposicionais" (GÍVON, 2012, p. 93). Assim, nas línguas, em geral, não raro, posições reservadas a Sujeito e a Tópico coincidem, pelo fato de tanto um quanto outro constituírem marcadores de continuidade tópica. Como comprova Givón (1976), a concordância entre Sujeito e verbo surge diacronicamente nas línguas como expediente gramatical, via reanálise de Tópico em Sujeito, e a gramaticalização de Tópicos em Sujeitos não significa que a língua perdeu a construção de tópico, mas sim que ela ganhou concordância gramatical como propriedade de codificação morfológica adicional do seu Sujeito gramatical.

Givón (2001) postula que a topicalidade de referentes não é propriedade de nível sentencial, mas de nível do discurso, o que equivale a dizer que um referente é tópico não porque ocorre como Sujeito ou Objeto; deve-se ao fato de ser tópico ao longo do discurso multiproposicional, propriedade apreensível em termos de acessibilidade referencial (recuperação anafórica do referente) e importância temática (persistência catafórica do referente). Contudo, segundo o autor, a posição de Sujeito (tópico primário) ou de Objeto (tópico secundário) guarda relação com o uso pragmático da ordenação de palavras no discurso. O autor esclarece ainda que, no interior de uma proposição encaixada, um referente, dada sua importância tópica, pode ser topicalizado (ou alçado, nos termos do autor) de sua posição argumental original para a de tópico marcado na oração principal, e, nesse ambiente sintático, vir a se comportar gramaticalmente como argumento do predicado principal.

É também na consideração dessas explicações cognitivo-funcionais de Langacker (1995) e de Givón $(1976,2001,2012)$ que se busca um tratamento para as CCS mostradas de (1) a (3). Assim, o usuário da língua, se escolhe conceptualizar uma cena a partir da perspectiva de um de seus participantes, a topicalização de referentes argumentais 
incidirá na codificação morfossintática da cena enunciada (Tipos-2 e 3 de CCS); se, ao contrário, escolhe conceptualizar a localização abstrata da própria cena, nenhum referente argumental ganha relevo comunicativo na codificação morfossintática da cena (Tipo-1 de CCS). Amparando-se nessa interpretação e com base em resultados de pesquisas anteriores (GONÇALVES, 2001, 2009, 2011, 2012, 2015, 2017), constituintes argumentais de predicado subordinado que ocorrem à esquerda da construção matriz passam a ser tratados como tópico marcado, abandonando-se, assim, o conceito de Alçamento em favor do de Topicalização, pelas seguintes razões: (i) insuficiência de critérios tipológicos de Alçamento no contraste de construções com e sem alçamento; (ii) maior relevância de fatores semântico-pragmáticos sobre morfossintáticos na diferenciação de CCS com e sem alçamento; (iii) natureza mais pragmática do que morfossintática do fenômeno de Topicalização (GONÇALVES, 2016, 2017).

\section{Rede de herança de construções argumentais}

O princípio da motivação evidencia o funcionamento relacional do sistema linguístico, por meio do qual um padrão sintático-semântico predominante estrutura diversos outros. Com base na observação do contraste entre os padrões construcionais em (5) e (6), reveladores de diferentes tipos de construção argumental, defende-se aqui que o esquema mais genérico [[ArgSuj] [Pred]], independentemente da ordenação e complexidade interna de suas subpartes, motiva uma ampla rede de construções, tanto simples como complexas, como exemplificam as ocorrências pertinentes a cada tipo.

(5) Construção simples [[ArgSuj] [Pred]]

a. [[meu quarto] sus [é simples] $\left.]_{\mathrm{PRED}}\right]$

[AC-028, L. 82]

b. [[eu]sus [visitava muita agência] ${ }_{\text {pRED }]}$

[AC-051, L. 45]

C. [[diferente $]_{\text {PRED }}$ [a cultura deles $]$ sus]

[AC-094, L. 133]

d. aí [[chegou $]_{\text {PRED }}$ [a hora do almoço] $]$ suJ $]$

[AC-08, L. 16]

(6) Construções complexas [[ArgSuj] [Pred]]

a. [[ele]sus [ficô(u) sabendo [que [[eu]sus [tinha me separado]PRED]]]PRED]

[AC-076, L.10]

b. [[você]sus [precisa de [[Ø]suJ [fazê(r) isso daqui... um ultra-som] preDE]] pred]

[AC-140, L. 76] 
C. [[parece $\left.]_{\text {PRED }}\left[q u e[[\text { o sabor }] \text { sus [é o(u)tro] }]_{\text {PRED }}\right]\right]$ suJ $]$

[AC-140, L. 352]

d. o médico achou que [[seria bom] $]_{\text {PRED }}$ [[o depoimento do paciente]sus [sair na internet $\left.]_{\text {PRED }}\right]$ sus]

[AC-152, L. 75]

e. [[o incrivel]sus [é [que[[ela]sus [não ficô(u) com medo] pred]]]

[AC-062, L. 167]

Do contraste entre as ocorrências em (5) e (6), observa-se, conforme Goldberg (1995), os seguintes tipos de ligação entre construções simples e complexas: (i) por polissemia, porque, entre os dois tipos de construção, o sentido específico de "relação de predicação" entre [ArgSuj] e [Pred] se mantém, de modo recursivo; (ii) por subpartes, porque, na construção mais ampla, [ArgSuj] e [Pred] subsistem como construções particulares; (iii) por instanciação, porque as subpartes da construção genérica [ArgSuj] e [Pred] permitem instanciar construções tanto simples quanto complexas; (iv) por extensão metafórica, porque construções sintagmáticas nucleadas por nomes, em posição tanto de Sujeito quanto de Objeto, metaforicamente se estendem e passam a admitir, nas mesmas posições, construções oracionais, codificando estado-de-coisas e proposições, e não somente referente nominais. Esse tipo de extensão metafórica requer, nesse passo, uma análise um pouco mais detalhada do caso específico das CCS formadas por [ArgSuj] oracional encaixado em construção matriz impessoal com função de [Pred], como as exemplificadas em (6c) e (6d) acima 5 .

A despeito de, entre formalistas, se considerar a inexistência de sujeitos oracionais em português (cf. KATO; MIOTO, 2000), é possível defender, de um ponto de vista cognitivo, que construções subjetivas se instanciam na língua por extensão metafórica, porque se desviam do protótipo da categoria Sujeito (cf. (5a,b) e (6a.b)), cuja função básica, na língua, é a de codificar, em construções nucleadas por nome, entidades do tipo indivíduo ${ }^{6}$. Em termos semântico-cognitivos, em uma construção argumental, entidade indivíduo, codificada por [ArgSuj] nominal, metaforicamente se estende e, numa instância de abstratização, passa a permitir a presença de entidades de ordem superior, como estado-de-coisas e proposições, codificados por [ArgSuj] oracional, tornando a construção

5 Para maior clareza, atente-se para o fato de que, na CCS, a construção [SUJ], identifica a construção subjetiva (encaixada) e a construção [PRED], a construção matriz.

6 Ontologicamente, entidade indivíduo, como de $1^{\text {a }}$ ordem, só pode ser avaliada pela sua existência, dadas suas propriedades perceptuais relativamente estáveis no espaço e no tempo; entidade estado-de-coisas, de $2^{\mathrm{a}}$ ordem, ocorre no espaço e no tempo e só pode ser avaliada em termos de sua realização, por referir eventos; proposição, como entidade de $3^{a}$ ordem, por referir construto mental, não tem localização espaço-temporal e só pode ser avaliada em termos de verdade/ falsidade (LYONS, 1977). 
argumental ainda mais complexa em sua constituição interna. Desse modo, em CCS, a construção matriz impessoal (forma não marcada de $3^{a}$ pessoa) expressa sempre um julgamento do usuário da língua (ou por ele atribuído a terceiros) sobre estado-de-coisas e proposição representados na construção encaixada.

Tomando-se (6c) e (6d) como exemplos do funcionamento de CCS, em (6c), a construção subjetiva [o sabor é outro] é uma proposição possível de ser verdadeira, com base no julgamento epistêmico do usuário da língua, expresso na construção matriz com o predicado parecer; já, em (6d), a construção subjetiva [o depoimento da paciente sair na internet] é um estado-de-coisas não realizado, mas julgado por terceiro (o médico) como "bom", como expressa o predicado da construção matriz. Assim, enquanto sobre proposições incidem predicados epistêmicos, sobre estado-de-coisas incidem predicados avaliativos, ambos podendo ser de base verbal ou nominal ${ }^{7}$. Não obstante as propriedades assimétricas que particularizam os três tipos de CCS aqui tratados, são as semelhanças entre eles que definirão, por "efeito de prototipia", o membro que melhor representa a categoria, como mostrado no quadro 2.

Quadro 2. Configurações de Construções Complexas Subjetivas

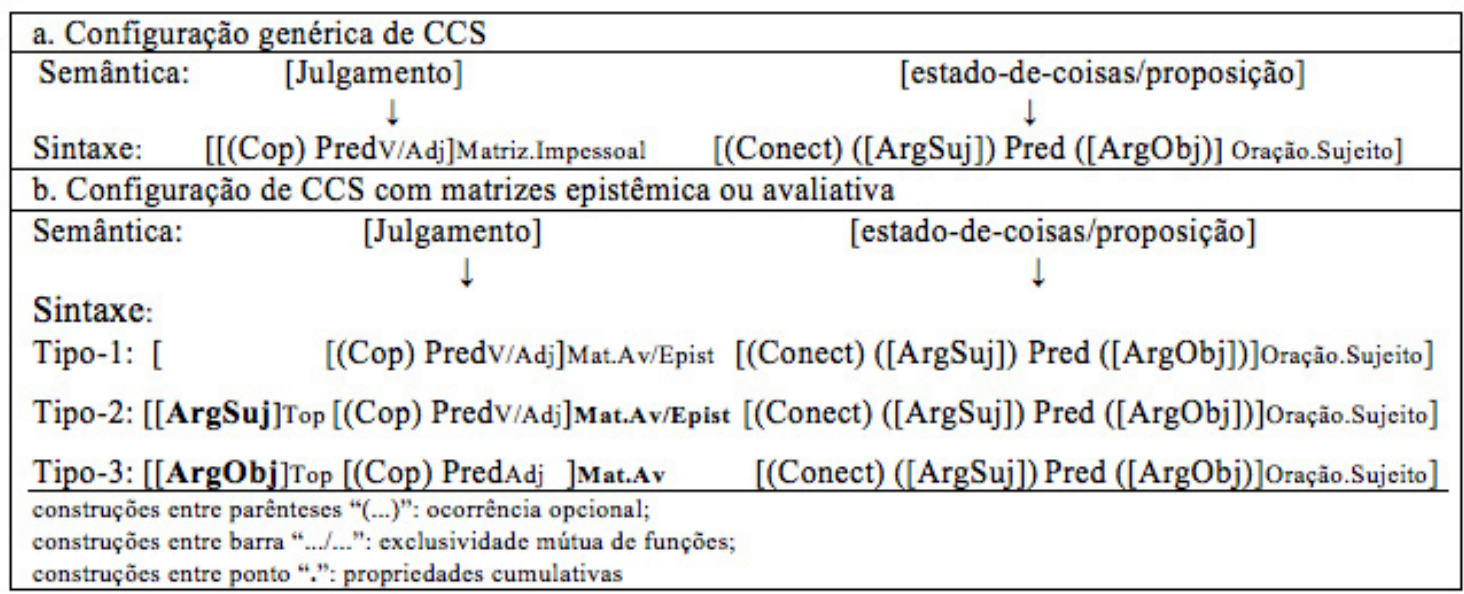

Fonte: Elaboração própria

De acordo com o quadro 2, o esquema genérico ou protótipo de CCS, em (a), prevê as seguintes propriedades de forma e função: (i) construção matriz impessoal (em $3^{a}$ pessoa do singular) de tipos variados de predicados em função predicativa (avaliativo, deôntico, epistêmico etc.); com cópula, se o predicado é adjetival ou nominal, ou sem, se o predicado é verbal; (ii) construção matriz com função semântico-pragmática de

7 É a semântica da construção matriz que confere à subordinada estatuto de estado-de-coisas ou de proposição (DIK, 1997). Adota-se, aqui, a classificação de predicados matrizes de Gonçalves et al. (2016). 
expressar algum tipo de julgamento (inter)subjetivo acerca do conteúdo da construção subjetiva, construído como estado-de-coisas ou como proposição, a depender de propriedades semânticas do predicado da construção matriz; (iii) presença ou ausência de conectivo ligando construção matriz e encaixada; complementizador que, se a construção encaixada é finita, e preposição de, para ou zero, se a construção encaixada é infinitiva; (iv) construção subjetiva encaixada à direita da matriz, mas possível de ocorrer à esquerda, se a infinitiva constituir tópico. Em (7), exemplificam-se CCS prototípicas.

(7) CCS prototípicas com diferentes tipos de predicados na construção matriz

a. [[ensiná(r) um prato]suBs [é complicado] PRED.Av]

[AC-143; L. 268-271]

b. aí eu falei pra mãe... - "olha mãe... a senhora viu que ela já veio com vermelho desde o prime(i)ro bimes:.tre ... não tem como passá(r) a M.L. ... mas [[é importante]PRED.Av] [que ela reprove]suв]" - porque a gente num mostra só o ponto negativo

[AC-086; L. 688-690]

c. [[basta] PRED.DEo [o governo tentá(r) fazê(r) o quê?]

[AC-057, L. 377]

d. [[Parece $]_{\text {PRED.EPIST }}$ [que a gente tá sempre queren(d)o mais $]$ suBu]

[AC-116, L. 333]

Em todas as construções em (7), a construção matriz predica sobre o conteúdo da construção subjetiva, qualificando-a com base em preceitos socioculturais: enquanto, em (7a) e (7b), expressa um julgamento avaliativo acerca do conteúdo dos estados-decoisas encaixados, em (7c), expressa um julgamento deôntico de um estado-de-coisas, passível de ser realizado por um agente moralmente responsável como uma obrigação. Já em (7d), o conteúdo proposicional encaixado é epistemicamente qualificado como possível, com base em crenças e conhecimento de mundo do usuário da língua, o que o descompromete da verdade que enuncia. Em termos cognitivos, a cena emoldurada em (7a) leva à topicalização da própria construção subjetiva, por seu conteúdo ser mais saliente no atendimento aos propósitos do ato comunicativo, enquanto, nas demais ocorrências, ganham relevo comunicativo o próprio julgamento e a cena emoldurada na construção encaixada (LANGACKER, 1995).

Ainda de acordo com o quadro 2, os padrões construcionais em (b), integrantes da categoria prototípica, particularizam CCS com matrizes epistêmica ou avaliativa, não somente pela forma, mas também pelas funções discursivo-pragmáticas que elas cumprem no ato comunicativo, como mostram as ocorrências de (1) a (3) e as de (8) a (10) dadas a seguir. 
(8) Tipo-1: CCS com matriz avaliativa e epistêmica sem topicalização

a. [[num foi fácil]MAT.Av. [a gente passá(r) esses onze anos]suBJ]

[AC-133; L. 70]

b. naquela época [[parece ]MAT.EPIST. [que tudo era mais fácil né?]suBJ]

[AC-082; L.151]

(9) Tipo-2: CCS com matriz avaliativa e epistêmica com topicalização Sujeito

a. como se faz é:: pra cuidá(r) de tanta planta já que [[você parece]MAT.EP. [que tem um amor tão grande por isso]suBJ]

$=$ [[parece] [que você tem um amor tão grande por isso]]

[AC-114; L.456]

b. [[o namoro]suJ.TOP. [é difícil]MAT.Av. [pra andá(r) pra frente né?]SUBJ]] ... eu a/ eu penso assim

= [[é difícil] [para o namoro andar pra frente]]

[AC-046, L. 414]

(10) Tipo-3: CCS com topicalização de Objeto

a. [[toalha] oBj.ToP [é complicAdo pa caramba]MAT.Av [pa dobrá(r)]suBJ]

$=$ [[é complicado] [pra dobrar toalha]]

[AC-016, L. 360]

Herdando traços das CCS prototípicas, construções matrizes impessoais dos Tipos- 1 e 2 são formadas por predicados tanto avaliativos (fácil, difícil,complicado) quanto epistêmicos (parecer), ao passo que as do Tipo-3, somente por predicados matrizes avaliativos. Outro aspecto que as diferencia diz respeito à ordenação sintática dos constituintes argumentais da construção subjetiva. Apesar de, nos três tipos, ser preservada a relação semântica de predicação entre o predicado da construção subjetiva e seus argumentos Sujeito e/ou Objeto, uma ruptura no arranjo convencional entre eles é observada nas CCS dos Tipos-2 e 3. Por razões discursivas e estruturais, Sujeito ou Objeto assumem posição pré-verbal, típica de Sujeito, na construção matriz impessoal, sem que isso leve a problema de interpretação semântica. Essa propriedade, em particular, é motivada por traços de herança advindos da forma e da função de construções argumentais que, na rede mais ampla, são mais esquemáticas e de ordem superior ao nível em que se encontram CCS, como se verá mais adiante. Tal traço diz respeito à preservação de propriedades argumentais da construção [ArgSuj], que, na rede de construções simples e complexas, tende a assumir sempre posição pré-verbal não-marcada (cf. (5) e (6)). Em construções prototípicas de CCS em rede, uma mesma posição pré-verbal encontra-se disponível à esquerda de construções com predicados matrizes impessoais, como em 
(7), e pode vir a ser ocupada por qualquer argumento com função de tópico (cf. (9) e (10)). Assim, parece mesmo inócua a discussão da primazia entre as funções Tópico e Sujeito do constituinte que ocorre à esquerda da construção matriz, pela simples contingência de ele ocorrer em posição pré-verbal.

No passo desses argumentos, não se deve ignorar, entretanto, que a forma dos padrões construcionais dos Tipos-2 e 3 pode ter algum impacto na estruturação das CCS, na medida em que se torna possível distinguir padrões mais e menos gramaticalizados no processo de combinação de suas subpartes. A rotinização de padrões mais gramaticalizados pode promover uma neoanálise de suas subpartes, motivada por processo de analogização ao padrão genérico das construções [[ArgSuj][Pred]], de forma a se restabelecer a sistematicidade da língua em que Sujeitos nominais referenciais tendem a preceder 0 predicado a que se ligam por razões de topicalidade (cf. (5a), (5b), (6a), (6b)).

\section{Rede de herança de construções argumentais simples e complexas}

Com base nas análises, postula-se, para CCS (em destaque), a participação em uma ampla rede de herança de construções argumentais, como mostrado na figura 2, a seguir, uma rede meronímica de partes-todo com relação múltipla de herança (BARĐDAL; GILDEA, 2015).

Figura 2. Rede meronímica de construções argumentais

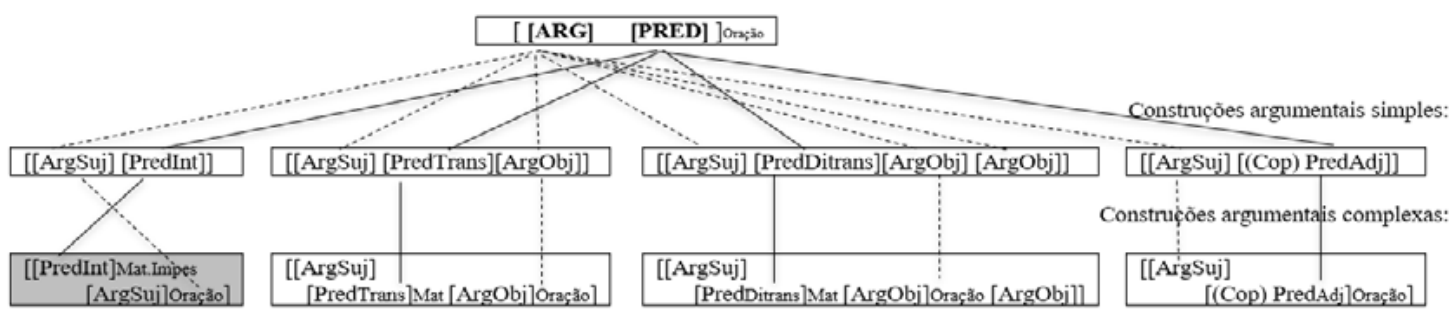

Fonte: Elaboração própria

Conforme se observa na figura 2, a rede de construções argumentais é estruturada em três níveis: (i) o esquema genérico [[Arg] [Pred]]oração é lexicalmente aberto e determina a regularidade do sistema, por constituir uma abstração das construções de nível mais baixo; suas subpartes [Arg] e [Pred], como construções independentes, estabelecem entre si relação semântica de predicação; (ii) o segundo nível abriga construções com menor grau de esquematicidade, para dar conta dos diferentes tipos de construções argumentais simples (intransitivas, transitivas, ditransitivas e predicativa); a construção [Pred] determina a estrutura argumental da construção oracional mais ampla pela função que tem de predicar sobre a construção [Arg]; as construções [ArgSuj], [ArgObj] e [Pred] são construções sintagmáticas lexicalmente abertas; (iii) no último nível, se situam as 
construções argumentais complexas, com grau menor de esquematicidade, em relação às construções do nível anterior, porque alguma subparte, [ArgSuj], [ArgObj] ou mesmo [Pred], com função predicativa, são construções oracionais, que, recursivamente, se instanciam obedecendo-se ao esquema genérico da rede.

Por fim, na configuração da rede, construções simples e complexas correspondentes herdam traços semânticos da relação de predicação representada no nível esquemático mais alto; traços de herança entre os dois níveis mais baixos se verificam em relação aos mesmos tipos sintático-semântico de predicado das construções e em relação à equivalência funcional, nos diferentes tipos de construção, entre subpartes construídas como sintagma e subpartes construídas como oração.

\section{Rede de herança de construções complexas subjetivas}

Da organização da rede mostrada na figura 2, cabe observar ainda que também tornam assimétricas as construções argumentais propriedades sintáticas, semânticas e pragmáticas de suas subpartes, tais como, posição na construção, tipos semânticos de predicados e distribuição de informação (topicalidade) da própria subparte e de seus constituintes internos. Tais propriedades, não relevantes na estruturação da rede mais ampla, são particularidades que devem ser consideradas na investigação própria de cada tipo de construção, como é o caso das CCS, que, em destaque na rede meronímica, segue detalhada na figura 3, em uma rede taxonômica de relação partes-parte (BARĐDAL; GILDEA, 2015), considerando as análises já desenvolvidas em subseção própria anterior.

Figura 3. Rede taxonômica de construções complexas subjetivas

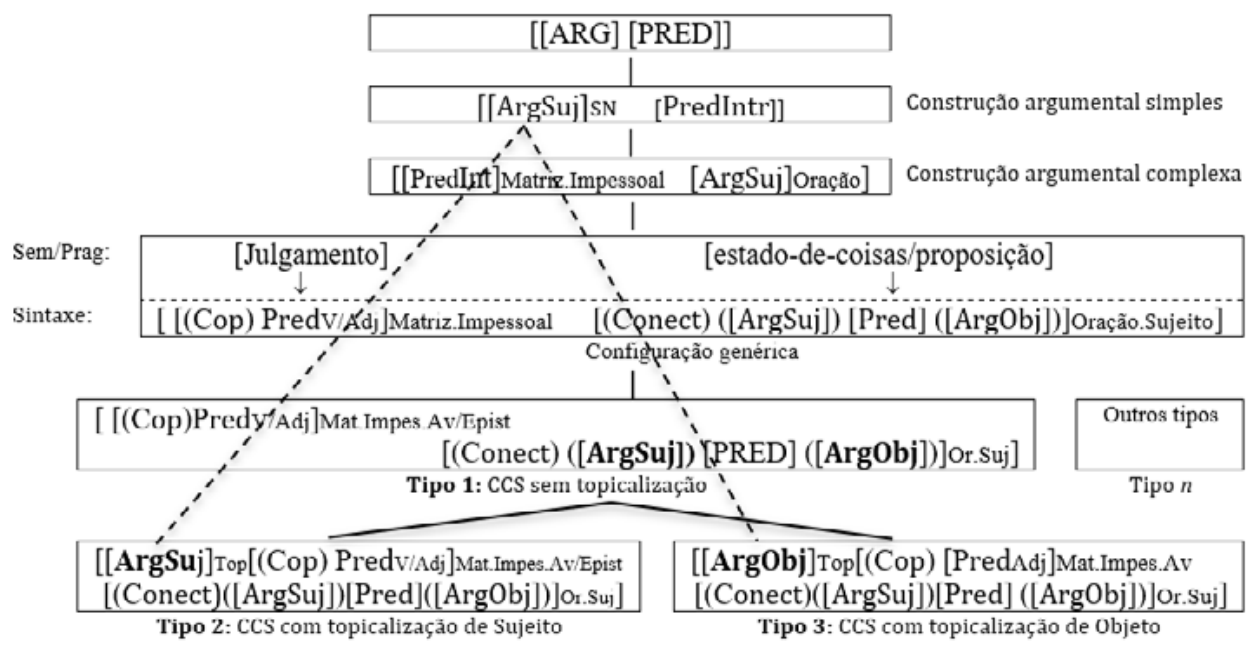

Fonte: Elaboração própria 
Expandindo a rede apresentada na figura 2 para, agora, focalizar a participação de CCS, o nível a partir do qual sua rede hierárquica se estabelece claramente reflete princípios cognitivos de organização em rede (cf. (4)), que assim se explicitam: (i) num nível superior, localiza-se o padrão esquemático mais geral de CCS prototípicas; (ii) no nível intermediário, situa-se o esquema de CCS com matriz epistêmica ou avaliativa, sem topicalização de constituintes argumentais (construções de Tipo-1); (iii) no mesmo nível mais baixo da rede, arranjam-se os padrões de CCS com Sujeito topicalizado em construções matrizes epistêmicas e avaliativas (construções de Tipo-2) e de CCS com Objeto topicalizado (Tipo-3) em construções matrizes somente avaliativas, ambos os tipos herdando traços de herança da construção mais esquemática [[ArgSuj][PredInt]], que motiva, nas CCS, [ArgSuj] e [ArgObj] ocorrerem à esquerda da construção matriz impessoal, por processo de analogização com a posição de [ArgSuj] topicalizado.

\section{Conclusão}

Com base no esquema de predicação [[Arg] [Pred]], totalmente abstrato, procurou-se traçar uma rede de construções argumentais, simples e complexas, para nela situar as CCS, expandidas em três níveis: (i) um nível esquemático geral, formulado para CCS prototípicas; (ii) um nível intermediário, para CCS com matrizes impessoais epistêmica ou avaliativa, sem topicalização de constituinte; (iii) um nível mais baixo, para dois subesquemas de topicalização de constituinte argumental, um para topicalização de Sujeito em matriz epistêmica ou avaliativa, e outro para topicalização de Objeto em matriz somente avaliativa. Evidencia-se, assim, que a hierarquização proposta para os padrões de CCS assenta-se em princípios cognitivos relevantes para formação de redes construcionais, assim interpretados:

(i) sob o Princípio da motivação maximizada, todos os tipos de CCS (Tipos-1,2 e3) encontramse sintaticamente relacionados pela projeção de traços da construção esquemática mais geral [[Arg] [Pred]], cujas subpartes mantém entre si relação semântica de predicação.

(ii) o Princípio de não-sinonímia revela que divergências sintáticas e equivalência semântica entre as construções do Tipo-1 e as dos Tipos-2 e 3 (de níveis diferentes na rede) refletem distinções pragmáticas, relacionadas à estrutura de informação de [ArgSuj] e [ArgObj] da construção encaixada; entre construções dos Tipo-2 e 3 (de mesmo nível na rede), divergências sintático-semânticas (como tipo de constituinte argumental e tipo semântico de matriz) refletem equivalência pragmática, relacionada à estrutura de informação e à saliência cognitiva, que justificam [ArgSuj] e [ArgObj] ocorrem em posição de tópico na construção matriz impessoal.

(iii) na base do Princípio do poder expressivo maximizado está o fato de diferentes padrões de CCS se encontrarem ligados numa mesma rede, porque o inventário desses padrões é maximizado para atender a propósitos comunicativos: se, na cena emoldurada na 
construção encaixada, nenhum constituinte argumental é comunicativamente saliente, a própria construção pode ou não ser topicalizada (construções prototípicas e construções do Tipo-1); se um dos participantes é comunicativamente saliente, ele assume propriedade tópica dentro do complexo oracional (construções dos Tipos-2 e 3);

(iv) por fim, o Princípio da economia maximizada explica o fato de CCS de diferentes padrões (Tipos-1, 2 e 3) poderem ser representadas em acordo com o padrão esquemático [[Arg][Pred]] mais amplo da rede de construções, que, pela sua produtividade na língua, sanciona construções simples e complexas de graus variados de esquematicidade, como são os casos de CCS, que, independentemente de tipos específicos de construção matriz e encaixada, tendem a preservar traços de forma e significado/função de construções de níveis mais altos na rede.

Em última análise, a disposição de construções em rede, como a aqui apresentada, revela que quanto mais alto o nível em que a construção se encontra, maior seu grau de esquematicidade, uma abstração de padrões específicos de níveis mais baixos, explicativa da variação e da gradiência de padrões encontrados em eventos de uso efetivo da língua. Prova-se, assim, a adequação da abordagem construcional também para o tratamento de construções complexas, uma agenda de pesquisa ainda a ser mais bem explorada dentro dos $M B U$, para dar conta de complexos oracionais de tipos distintos.

\section{REFERÊNCIAS}

BARLOW, M.; KEMMER, S. Introduction: a usage-based conception of language. In: BARLOW, M.; KEMMER, S. (ed.). Usage based models of language. Stanford: CSLI Publications, 2000. p. 7-25.

BARĐDAL, J.; GILDEA, S. Diachronic construction grammar: epistemological context, basic assumptions and historical implications. In: BARĐDAL, J. et al. (ed.). Diachronic construction grammar. Philadelphia: John Benjamins, 2015. p. 1-50.

BYBEE, J. Língua, uso e cognição. Tradução Maria Angélica Furtado da Cunha e Sebastião Carlos Leite Gonçalves. São Paulo: Cortez, 2016.

CROFT, W. Radical Construction grammar: syntactic theory in typological perspective. Oxford: Oxford University Press, 2001.

DIK, S. C. The Theory of Functional Grammar. Part 2. Complex and derived constructions. [Kees Hengeveld (ed.)]. Berlin: Mouton de Gruyter, 1997. 
GIVÓN, T. Syntax: an introduction. v. 1 e 2. Philadelphia: John Benjamins, 2001.

GIVÓN, T. A compreensão da gramática. Tradução Maria Angélica Furtado da Cunha, Mário Eduardo Martelotta e Felipe Albani. São Paulo: Cortez/Natal: EDUFRN, 2012.

GIVÓN, T. Topic, pronoun and grammatical agreement. In: LI, C. (ed.). Subject and topic. New York: Academic Press, 1976. p. 149-188.

GOLDBERG, A. Constructions: a new theoretical approach to language. Trends in Cognitive Sciences, v. 7, n. 5, p. 219-224, 2003.

GOLDBERG, A. Constructions: a construction grammar approach to argument structure. Chicago: Chicago of University Press, 1995.

GONÇALVES, S. C. L. O estatuto variável de construções com e sem alçamento: uma abordagem sociofuncionalista. D.E.L.T.A., São Paulo, v. 33, n. 3, p. 1291-1321, 2017.

GONÇALVES, S. C. L. Posição de sujeito e objeto em construções complexas subjetivas. Revista Linguística, Rio de Janeiro, v. esp., p. 192-215, 2016.

GONÇALVES, S. C. L. Orações completivas em posição argumental de sujeito e o alçamento a sujeito sob perspectiva funcional. In: HORA, D.; PEDROSA, J.; LUCENA, R. (org.). ALFAL 50 anos: contribuições para os estudos linguísticos e filológicos. João Pessoa: Ideia, 2015. p. 367-417.

GONÇALVES, S. C. L. Orações subjetivas e mudança de padrões na história do português. In: SOUZA, E. R. (org.). Funcionalismo linguístico: análise e descrição. São Paulo: Contexto, 2012. p. 93-118.

GONÇALVES, S. C. L. Orações subjetivas: variância e invariância de padrões na fala e na escrita. Revista da Abralin, Campinas, v. 10, n. 1, p. 87-11, 2011.

GONÇALVES, S. C. L. Aspectos da subordinação sentencial sob uma perspectiva diacrônica: o caso das orações em posição argumental de sujeito. In: CASTILHO, A. T. (org.) História do português paulista. Campinas: Editora da UNICAMP, 2009. p. 585-594.

GONÇALVES, S. C. L. Banco de dados Iboruna: amostras eletrônicas do português falado no interior paulista. 2007. Disponível em: http:://www.iboruna.ibilce.unesp.br. Acesso em: 20 jan. 2020. 
GONÇALVES, S. C. L. Orações subjetivas e teoria dos protótipos. Scripta, Belo Horizonte, v. 9, n. 1, p. 183-196, 2001.

GONÇALVES, S. C. L.; OLIVEIRA, T. P. Por uma abordagem de construções complexas em perspectiva construcional. Working papers em linguística, Florianópolis, v. 21, n. 1, 2020 [no prelo].

GONÇALVES, S. C. L.; SOUSA, G. C.; GALVÃO, V. C. C. As construções subordinadas substantivas. In: NEVES, M. H. (org.). A construção das orações complexas. São Paulo: Contexto, 2016. p. 69-121.

KATO, M. A.; MIOTO, C. A inexistência de sujeitos oracionais. Laços, Rio de Janeiro, p. 61-90, 2000.

LANGACKER, R. Foundations of cognitive grammar: theoretical prerequisites. v. 1. Stanford: Stanford University Press, 1987.

LANGACKER, R. Raising and transparency. Language, v. 71, n. 1, p. 1-62, 1995.

LYONS, J. Semantics. Cambridge: Cambridge University Press, 1977.

TRAUGOTT, E. C. Grammaticalization, constructions and the incremental development of language: suggestions from the development of degree modifiers in English. In: ECKARDT, R.; JäGER G.; VEENSTRA, T. (ed.). Variation, Selection, Development - Probing the Evolutionary Model of Language Change. Berlin/New York: Mouton de Gruyter, 2008. p. 219-250.

TRAUGOTT, E. C.; TROUSDALE, G. Constructionalization and constructional changes. Oxford: Oxford University Press, 2013. 